https://doi.org/10.34024/prometeica.2021.22.11653

\title{
EXPLORANDO ESPACIOS FICCIONALES
}

\author{
EXPLORANDO ESPAÇOS FICCIONAIS
}

\section{EXPLORING FICTIONAL SPACES}

Han pasado muchos meses ya de aquel Encuentro de Investigación en Humanidades sobre Ficción, ficciones y ficcionalidad realizado en Mar del Plata en 2019, en el que empezamos junto a Omar Murad y Nicolás Lavagnino a diagramar el número especial que hoy felizmente publicamos sobre Teorías de la ficción. El encuentro, y en gran medida el presente número, se articulan a partir del trabajo sostenido de intercambio académico de tres Grupos de Investigación pertenecientes a la Universidad de Comahue, la Universidad Nacional de Mar del Plata y la Universidad de Buenos Aires, y se enriquece con la participación activa de Mariana Castillo Merlo y Daniel Scheck, así como de investigadores reconocidos en el tema de diferentes universidades de España, Estados Unidos, Finlandia, entre otros.

La presente propuesta para un número temático sobre teorías de la ficción resulta convocante a la luz de la atención que este antiguo tópico de la filosofía ha recibido en la reflexión contemporánea. La diversidad de posiciones en torno a la ficción y su valor para el conocimiento y el comportamiento humano en general la vuelven un ámbito vivo de discusión e interés en el que abrevan las más diversas tradiciones.

Una teoría articulada de la ficción es todavía un proyecto inconcluso. Tal vez el último en intentarlo fue Hans Vaihinger en su mal conocida Phylosophy of 'as if' de 1911. Influenciado por Bentham y Nietzsche, sus ideas sobre el papel de la ficción en la ciencia y el conocimiento en general fueron discutidas por el Círculo de Viena y tuvo un amplio, aunque no del todo reconocido, impacto en las ideas novel positivismo lógico. El problema del valor de la ficción para el conocimiento, sin embargo, se remonta a Platón y la expulsión de los poetas de su república ideal.

En la actualidad, hallamos varias teorías de la ficción no del todo compatibles entre sí, pero con algunos rasgos comunes. La posición tradicional tiende a oponer este concepto con el de 'realidad', generando una tensión de mutua oposición entre ambos. Se desconecta de esta forma la creatividad y la imaginación del conocimiento y la realidad y se las envía al ámbito de la ilusión y las apariencias. Otra posición se remonta a Aristóteles y considera productivamente a la capacidad de la ficción para modelar las diversas dimensiones de lo real. Aquí 'realidad' no se opone a 'ficción', sino que aquella es un producto de esta. Dicha tradición, ya en la antigüedad pone en conexión la capacidad creativa de la poética con la argumentativa y especulativa de la retórica, luego es recuperada por la retórica latina y más tarde por el humanismo renacentista, finalmente condensada en la máxima viqueana verum ipsum factum. Al contrario de lo que sostuvo Descartes, para Vico el hombre sólo conoce lo que él mismo ha realizado, es decir, el mundo como un sistema de signos por él elaborado. En esta vena, las dimensiones prácticas de la acción, ética y política, se encuentran con el conocimiento y el arte en general.

En el panorama contemporâneo, esta rica tradición es recuperada por E. Auerbach, W. Benjamin o M. Heidegger y sus discípulos, H-G. Gadamer, H. Arendt, H. Blumenberg, entre otros. Asimismo, la tradición francesa desarrolló una teoría de la ficción heredada de Nietzsche y Blanchot, entre otros, y cultivada recientemente, por ejemplo, por Foucault, Derrida o Rancière. El New Criticism también ha contribuido a la teoría de la ficción. Su enorme influencia se deja ver en la crítica literaria, las ciencias sociales, la historia, y en intelectuales de la talla de N. Frye, K. Burke, R. Rorty, o H. White. En todos 
los casos, la teoría de la ficción es acompañada de una profunda reflexión sobre el lenguaje y la consideración del hombre como un animal simbólico.

Las teorías de la ficción ponen en diálogo cuestiones epistemológicas, que versan por ejemplo sobre la justificación del conocimiento como una práctica social, con la estética o, mejor aún, con la imaginación poética y sus capacidades. Borran los límites estrechos que separan la literatura de la ciencia y recuperan el poder heurístico de la metáfora y la literatura.

Generar un panorama completo del marco de debates que actualmente se desarrollan en torno de la ficción resulta probablemente una tarea algo oceánica que este número no pueda realizar. Sin embargo, a lo largo de los diferentes trabajos que lo componen, pueden recuperarse líneas de abordaje fundamentales para el tratamiento de la ficción y de los problemas conceptuales que se plantean en el pensamiento contemporáneo en relación al estatuto ontológico de lo ficcional, su función cognitiva, los efectos performáticos que expresa al dar un marco simbólico a la praxis, su injerencia desde una perspectiva emocional y estética, y algunas aproximaciones a su vínculo con otras esferas del pensamiento como lo son la filosofía del arte, la ética, la filosofía de la historia, la semiótica, las narrativas emergentes, entre otras.

Esperamos que el número resulte de su interés y constituya un aporte al marco de reflexión y debates sobre el tema.

Emiliano Aldegani

(Universidad Nacional de Mar del Plata) emilianoaldegani@gmail.com 